\title{
Myoinositol with Metformin and Myoinositol alone in infertile PCOS women undergoing ovulation induction cycles: A comparative study
}

\author{
Dr. Gade Pramod R', Dr. Aher Gautam $S^{2}$, Dr. Vazifdar Sharmeen ${ }^{3}$
}

\begin{abstract}
${ }^{1}$ Assistant Professor, Department of Obstetrics \& Gynecology, DVVPF's Medical College, Ahmednagar, MHS, India
${ }^{2}$ Professor \& Head, Department of Obstetrics \& Gynecology, DVVPF's Medical College, Ahmednagar, MHS, India

${ }^{3}$ PG Resident (Year II), Department of Obstetrics \& Gynecology, DVVPF's Medical College, Ahmednagar, MHS, India
\end{abstract}

\begin{abstract}
Background: This was a prospective observational study conducted over a twelve-month duration in our institute to compare the combined effect of metformin and myoinositol with metformin alone. Method: A total of sixty patients were included in the study, and they were divided into two groups depending on whether they were given the combination or the single drug. Group A $(n=30)$ was given Myoinositol $600 \mathrm{mg}+$ Metformin $500 \mathrm{mg}$ thrice a day, and Group B ( $n=30)$ was given only Myoinositol $600 \mathrm{mg}$ thrice a day. The outcome measure was clinical pregnancy rate and improvement in clinical and hormonal parameters after drug therapy. Results: BMI $(\mathrm{p}<0.01)$, modified Ferriman Gallaway score ( $p>0.05)$, and the was a significant improvement in the hormonal parameters (LH,FSH) in both the groups and the levels were found to be comparable after a period of 6 months. The clinical pregnancy rate after six cycles of ovulation was significantly higher in Group A as compared to Group B. In Group A, the total clinical pregnancy rate was $43.33 \%$, and in Group B, it was $26.67 \%$, respectively, and the end of 6 months and the difference was statistically significant $(p=<0.01)$ Conclusion: Equal response in reduction of hormonal levels and clinical and laboratory parameters were seen in both groups, while better results in terms of clinical fertility rates were observed in the group that was given a combination of myoinositol with metformin.
\end{abstract}

KEYWORDS: Myoinositol; Metformin; Polycystic ovarian syndrome; Infertile; Ovulation induction

\section{INTRODUCTION}

$\mathrm{P}$ olycystic ovarian syndrome (PCOS) is the common reason for infertility with anovulatory cycles, and prevalence among infertile women is $15-20 \%[1,2]$. This syndrome was first described by Stein and Leventhal in 1931. It is a disorder characterized by excessive secretion of androgens by the ovaries, oligomenorrhea, anovulation/oligo- anovulation, and insulin resistance and with variable clinical manifestations like oligomenorrhoea, hirsutism, acne [3]. The pathogenesis of PCOS has not been completely elucidated and is multifactorial, with the genetic and environmental factors being implicated. The resistance to insulin is thought to be due to problems in the receptors of insulin and post-receptor components of the signaling pathway of insulin $[4,5]$.

Hyperinsulinemia due to resistance to insulin occurs in roughly $80 \%$ of PCOS women with central obesity, as well as in $30-40 \%$ of thin women who have been diagnosed with PCOS [6]. Hyperinsulinemia leads to, increase in thecal androgen response to $\mathrm{LH}$, increased concentration of free androgen, increases circulating level of IGF-I, collectively hyperandrogenism [7]. Because hyperinsulinemia often plays a role in the pathogenesis of PCOS, insulin-sensitizing agents have been tried along with oral ovulation induction agents in anovulatory infertile PCOS. Among insulin sensitizers, metformin and Myoinositol have been studied most extensively [8].

Correspondence: Dr Gade Pramod, Assistant Professor, Department of Obstetrics and Gynecology, DVVPF's Medical College, Ahmednagar, MHS, India, Email: pramodgade8@gmail.com

eISSN: 2395-0471

pISSN: 2521-0394

DOI: $10.31878 /$ ijcbr.2021.72.02
(C) Authors; 2021. (CC BY-NC-SA 4.0)

This is an Open Access article which permits unrestricted non-commercial use, provided the original work is properly cited. 
Metformin act by decreased hepatic gluconeogenesis, increased insulin sensitivity, decrease insulin-induced fatty acid oxidation. Myo-inositol acts by a membrane-associated sodium-dependent inositol co-transporter GLUT4 as the second messenger of insulin signal and decreases hyperinsulinemia improves ovarian function decreases LH/FSH ratio, reduces serum androgens [9].

As the two insulin sensitizers act through different mechanisms, these may be combined to act synergistically to improve metabolic and reproductive outcomes in infertile PCOS women. The present study was planned to study the effect of combined Myo-inositol and metformin as compared to myo-inositol alone with regards to their reproductive outcome and positive changes in metabolic and hormonal parameters in PCOS women with infertility who are undergoing cycles for ovulation induction

\section{Material And Methodology}

Study design: This was a prospective observational, comparative clinical study.

Ethics approval: The institutional ethics committee approves the study

Study period: Conducted from November 2019 to November 2020

Locus of study: Department of Obstetrics and Gynaecology, Dr. Vithalrao Vikhe Patil Medical College, Ahmadnagar.

Study population: Infertile PCOS women (according to Rotterdam criteria) attending outpatient departments were screened for the study.

Inclusion criteria: Age between 20-36 years who failed to conceive for $>12 \mathrm{mth}$ and bilateral patent tubes on hysterosalpingography/laparoscopy.

Exclusion criteria: Thyroid disorder, Hyperprolactinemia, Male factor infertility, Type 1 or Type 2 DM, Pregnancy, Deranged kidney or liver function test, Cushing's disease, Congenital Adrenal Hyperplasia, and androgen-secreting neoplasms were excluded

Sample Size: Sample size was calculated by open-epi software. The prevalence of PCOS women with infertility was found to be $17.6 \%$ [11].

Sample size $\mathbf{n}=[\mathrm{DEFF} * \mathrm{~Np}(1-\mathrm{p})] /[(\mathrm{d} 2 / Z 21-$ $\left.\mathrm{a} / 2 *(\mathrm{~N}-1)+\mathrm{p}^{*}(1-\mathrm{p})\right]$

(Design effect (for cluster surveys-DEFF): 1 , Confidence limits as \% of 100 (absolute $\pm \%$ ) (d):10\%, Hypothesized \% frequency of outcome factor in the population (p) $17.6 \% \pm 10$, Population size (for finite population correction factor or fpc) (N): 1000000, CI: 95\%,
Calculated sample size is 56 , Final sample size $=60\}$

Grouping: The patients who fell into the eligibility criteria were randomly divided into two study groups, i.e., Group A $(n=30)$, that received Myoinositol 600mg+ Metformin $500 \mathrm{mg}$ thrice a day. Group B $(n=30)$ was given only Myoinositol $600 \mathrm{mg}$ thrice a day.

Methodology: Taking detailed history pertaining to PCOS and infertility, menstrual cycle length. Physical examination, including weight, height, BMI $(\mathrm{Kg} / \mathrm{m} 2)$, hirsutism scoring (modified Ferriman Galway scoring), was recorded. Patients were advised to keep a record of menstrual cycles and weight.

Baseline investigations included $\mathrm{CBC}$, Blood sugar fasting, fasting serum insulin. The hormonal analysis included serum FSH, LH, TSH, Prolactin, Testosterone, SHBG, and AMH done on days $2-3$ of the previous menstrual cycles.

All patients were on the same drug according to the group allocated and, in addition, were given ovulation induction. For ovulation induction, tablet Letrozole $2.5 \mathrm{mg}$ was started from day 3 to day 7 of the cycle. Transvaginal ultrasound (TVS) was done from day 9 of the cycle, and patients were followed with serial TVS till a mature follicle $(>18 \mathrm{~mm}$ ) was documented. Inj HCG 5000 IU was given when the mature follicle was documented. Patients were advised to maintain intercourse about $24 \mathrm{~h}$ following ovulation trigger to the next two more days. UPT was done after overdue menses. Those with a negative urine pregnancy test and inadequate response were recruited for the second cycle of OVI with Letrozole $5 \mathrm{mg}$ in addition to gonadotropins if the patient did not ovulate in the first cycle till the maximum of six cycles. After every subsequent cycle, patients who conceived were excluded from subsequent analysis. A record of dropouts was maintained.

The primary outcome measure was the clinical pregnancy rate. Secondary outcomes included improvement in clinical and hormonal parameters after drug therapy. Data statistical analysis was done. A p-value $<0.05$ was considered statistically significant.

\section{RESUlTS}

A total of 96 patients with infertile PCOS were screened for this study. According to inclusion and exclusion criteria, 60 infertile PCOS women were selected for the study and were randomly assigned in two groups. Group A $(n=30)$ was given Myoinositol $600 \mathrm{mg}+$ Metformin $500 \mathrm{mg}$ thrice a day, and Group B $(n=30)$ was given only Myoinositol $600 \mathrm{mg}$ thrice a day. As shown in table 1, the baseline characteristics of the 
patients were comparable in both groups.

Table 1: Baseline demographic and clinical characteristics between two groups

\begin{tabular}{|l|l|l|l|}
\hline Characteristics & Group A & Group B & p-Value \\
\hline Age (years) & $26.8 \pm 8.3$ & $26.2 \pm 7.14$ & $>0.05$ \\
\hline BMI (kg/m2) & $26.2 \pm 12.4$ & $25.9 \pm 11.3$ & $>0.05$ \\
\hline $\begin{array}{l}\text { Duration of } \\
\text { infertility (Yrs) }\end{array}$ & $3.2 \pm 0.8$ & $3.8 \pm 0.8$ & $>0.05$ \\
\hline $\begin{array}{l}\text { Menstrual cycle } \\
\text { length (Days) }\end{array}$ & $36.2 \pm 8.8$ & $35.4 \pm 9.2$ & $>0.05$ \\
\hline $\begin{array}{l}\text { Modified } \\
\text { Ferriman } \\
\text { Gallaway score }\end{array}$ & $9.3 \pm 2.5$ & $10.3 \pm 1.9$ & $>0.05$ \\
\hline
\end{tabular}

$\mathrm{P}>0.05$ is statistically not significant.

After six months, the length of the menstrual cycle was found to have improved significantly in Group A in comparison to Group B (p < 0.01).

Table 2: Improvements in clinical parameters

\begin{tabular}{|l|l|l|l|l|}
\hline Parameters & Group A & Group B & Group A & Group B \\
\cline { 2 - 5 } & At start & $\begin{array}{l}\text { After 6 } \\
\text { Months }\end{array}$ & At start & $\begin{array}{l}\text { After 6 } \\
\text { Months }\end{array}$ \\
\hline $\begin{array}{l}\text { Body mass } \\
\text { index (kg/m2) }\end{array}$ & $26 \pm 12.4$ & $23.2 \pm 9.5$ & $25.9 \pm 11.3$ & $24.2 \pm 9.6$ \\
\hline $\begin{array}{l}\text { Modified } \\
\text { Ferriman } \\
\begin{array}{l}\text { Gallaway } \\
\text { score }\end{array}\end{array}$ & $9.3 \pm 2.5$ & $8.2 \pm 1.7$ & $10.3 \pm 1.8$ & $9.2 \pm 2$ \\
\hline
\end{tabular}

Table 3: Improvement in hormonal parameters

\begin{tabular}{|c|c|c|c|c|}
\hline \multirow[t]{2}{*}{ Parameters } & Group A & Group B & Group A & Group B \\
\hline & At start & $\begin{array}{l}\text { After } 6 \\
\text { Months }\end{array}$ & At start & $\begin{array}{l}\text { After } 6 \\
\text { Months }\end{array}$ \\
\hline LH (mIU/ml) & $14.3 \pm 1.9$ & $7.83 \pm 1.9$ & $15.4 \pm 1.4$ & $8.8 \pm 1.8$ \\
\hline p-value & \multicolumn{2}{|c|}{$<0.01$} & \multicolumn{2}{|c|}{$<0.01$} \\
\hline $\begin{array}{l}\text { FSH (mIU/ } \\
\mathrm{ml})\end{array}$ & $7.2 \pm 2.6$ & $4.48 \pm 1.7$ & $7.9 \pm 2.4$ & $4.6 \pm 2$ \\
\hline p-value & \multicolumn{2}{|c|}{$<0.01$} & \multicolumn{2}{|c|}{$<0.01$} \\
\hline LH/FSH ratio & $2.2 \pm 0.6$ & $1.75 \pm 0.4$ & $2.3 \pm 0.6$ & $1.7 \pm 0.5$ \\
\hline p-value & \multicolumn{2}{|c|}{$<0.01$} & \multicolumn{2}{|c|}{$<0.01$} \\
\hline $\begin{array}{l}\text { Testosterone } \\
(\mathrm{ng} / \mathrm{dl})\end{array}$ & $0.6 \pm 0.1$ & $0.32 \pm 0.2$ & $0.5 \pm 0.1$ & $0.3 \pm 0.2$ \\
\hline p-value & \multicolumn{2}{|c|}{$<0.01$} & \multicolumn{2}{|c|}{$<0.01$} \\
\hline $\begin{array}{l}\text { SHBG } \\
(\mathrm{nmol} / \mathrm{L})\end{array}$ & $12.6 \pm 7.4$ & $22.2 \pm 6.2$ & $13.1 \pm 6.2$ & $23.1 \pm 5.9$ \\
\hline p-value & \multicolumn{2}{|c|}{$<0.01$} & \multicolumn{2}{|c|}{$<0.01$} \\
\hline Sr AMH & $8.2 \pm 5.1$ & $5.62 \pm 1.1$ & $8.5 \pm 6.3$ & $6.1 \pm 1.4$ \\
\hline p-value & \multicolumn{2}{|c|}{$<0.01$} & \multicolumn{2}{|c|}{$<0.01$} \\
\hline $\begin{array}{l}\text { Blood sugar } \\
\text { fasting }(\mathrm{mg} / \mathrm{dl})\end{array}$ & $\begin{array}{l}99.52 \\
\pm 17.4\end{array}$ & $\begin{array}{c}81.5 \pm \\
24.2\end{array}$ & $\begin{array}{c}98.5 \pm \\
17.4\end{array}$ & $91.5 \pm 14.9$ \\
\hline p-value & \multicolumn{2}{|c|}{$<0.01$} & \multicolumn{2}{|c|}{$<0.01$} \\
\hline $\begin{array}{l}\text { Insulin fasting } \\
(\mathrm{uIU} / \mathrm{dl})\end{array}$ & $\begin{array}{c}11.68 \pm \\
3.5\end{array}$ & $\begin{array}{c}8.14 \pm \\
4.3\end{array}$ & $11 \pm 3.7$ & $9.5 \pm 6.2$ \\
\hline p-value & \multicolumn{2}{|c|}{$<0.01$} & \multicolumn{2}{|c|}{$<0.01$} \\
\hline
\end{tabular}

Int. j. clin. biomed. res. 2021;7(2):6-10
Improvement in fasting blood sugar and insulin levels was statistically insignificant. The clinical parameters, BMI $(p<0.01)$, modified Ferriman Gallaway score $(p>0.05)$, and the was a significant improvement in the hormonal parameters in both the groups and the levels were found to be comparable after a period of 6 months (Table 2).

TABLE 4: Per cycle analysis of ovulation induction cycles between two groups.

\begin{tabular}{|l|c|c|c|c|c|}
\hline Prameter & \multicolumn{2}{|c|}{ Group } & \multicolumn{2}{c|}{ Group A } & \multirow{2}{*}{ P- } \\
\cline { 2 - 5 } & A & B & A & B & \multirow{2}{*}{ Value } \\
\cline { 2 - 5 } & $\begin{array}{c}\text { Base- } \\
\text { line }\end{array}$ & $\begin{array}{c}\text { After 6 } \\
\text { months }\end{array}$ & $\begin{array}{c}\text { Base- } \\
\text { line }\end{array}$ & $\begin{array}{c}\text { After 6 } \\
\text { months }\end{array}$ & \\
\hline Conception & 0 & 13 & 0 & 8 & $<0.01 *$ \\
\hline Primary & 0 & 11 & 0 & 7 & $<0.01 *$ \\
\hline Secondary & 0 & 2 & 0 & 1 & $>0.05$ \\
\hline
\end{tabular}

${ }^{*}$ Signgicant

The clinical pregnancy rate after six cycles of ovulation was significantly higher in Group A as compared to Group B. In Group A, the total clinical pregnancy rate was $43.33 \%$, and in Group B, it was $26.67 \%$, respectively, and the end of 6 months and the difference was statistically significant $(\mathrm{p}=<0.01)$ Table 4 .

\section{Discussion}

TThe present study shows a significantly higher live birth rate in women who receive the combination of metformin and Myo-inositol as compared to myo-inositol alone. Both metformin and Myo-inositol are insulin sensitizers. The mechanism of action of the two is different.

PCOS is one of the most common endocrine disorders that affect women in their reproductive period [10]. Its characteristics are hyperandrogenism, anovulation for a prolonged period, and menstrual cycle irregularities [11].

Insulin receptor phosphorylation is found to be defective in about half of the patients with PCOS. 12 Multiple trials have shown that insulinsensitizing agents, like metformin and MI, are the first-line treatment to normalize menstrual cycles in women who have PCOS [13]. Out of the patients suffering from amenorrhoea, most cases had spontaneous onset of menstruation. Most of the patients observed spontaneous menses within two months of treatment [14]. There was a statistically significant improvement in pregnancy rates after 24 weeks of treatment in patients treated with metformin and myoinositol [15].

In a study conducted by Chirania et al. in twentytwo PCOS patients with menstrual irregularities achieved regular menses on their own, and most patients with infertility issues conceived. A vast reduction was also found in body weight, 
fasting insulin, and acne. None of the patients required discontinuation of the drug due to any intolerable side effects [16].

In a study conducted by Thakur $\mathrm{S}$ et al., they found a significant improvement in parameters like irregular menstruation, skin changes, rate of conception, LH/FSH ratio, sensitivity to insulin, and HOMA-IR after six months of treatment in each of the three groups. However, it was observed that there was a better improvement in cases that were given a combination of metformin and myoinositol than myoinositol and metformin individually [15].

Metformin and myoinositol are both insulin sensitizers with different mechanisms of action [8]. Various studies confirm that myoinositol is an effective alternative in treating PCOS patients and a safe and secure drug as no side effects could be observed in the standard dosages. On the other side easy compliance results in a better outcome in the management of ovulation, hyperandrogenism, and metabolic parameters in patients with PCOS [17]. Our study shows a significantly higher live birth rate in women who received the combination of metformin and myoinositol as compared to metformin alone. Improved menstrual cyclicity was noted in both groups but was higher in the combination group. Improved ovulation may be the reason for spontaneous menses and a higher pregnancy rate in the combination group.

\section{Conclusion}

The combined action of myoinositol and metformin has resulted in a significant reduction in the dose of the drug to be given but without affecting the drug's efficacy. We observed equal response in reduction of hormonal levels and clinical and laboratory parameters in both the groups, while better results in terms of clinical fertility rates were observed in Group A myoinositol with metformin. Further research in this regard is needed for better evaluation. We recommend a multi-centric study with a longer follow-up duration.

\section{Conflict of interest : Nil}

\section{Source of funding : Nil}

\section{REFERENCES}

1. Hull MG. Epidemiology of infertility and polycystic ovarian disease: endocrinological and demographic studies. Gynecological Endocrinology. 1987;1(3):235-452.

2. Angik R, Jajoo SS, Hariharan C, Chimote A. A comparative study of metabolic and hormonal effects of myoinositol vs. metformin in women with polycystic ovary syndrome: a randomised controlled trial. Int $\mathrm{J}$ Reprod
Contracept Obstet Gynecol. 2015;4(1):18994

3. Tehrani FR, Simbar M, Tohidi M, Hosseinpanah F, Azizi F. The prevalence of polycystic ovary syndrome in a community sample of Iranian population: Iranian PCOS prevalence study. Reproductive Biology and Endocrinology. 2011;9(1):1-7

4. Dunaif A, Xia J, Book CB, Schenker E, Tang Z. Excessive insulin receptor serine phosphorylation in cultured fibroblasts and in skeletal muscle. A potential mechanism for insulin resistance in the polycystic ovary syndrome. The Journal of clinical investigation. 1995;96(2):801-10

5. Brettenthaler N, De Geyter C, Huber PR, Keller U. Effect of the insulin sensitizer pioglitazone on insulin resistance, hyperandrogenism, and ovulatory dysfunction in women with polycystic ovary syndrome. The Journal of Clinical Endocrinology \& Metabolism. 2004;89(8):3835-40

6. Papaleo E, Unfer V, Baillargeon JP, Fusi F, Occhi F, De Santis L. Myo-inositol may improve oocyte quality in intracytoplasmic sperm injection cycles. A prospective, controlled, randomized trial. Fertility and sterility. 2009;91(5):1750-4

7. Hull MG. Epidemiology of infertility and polycystic ovarian disease: endocrinological and demographic studies. Gynecological Endocrinology. 1987;1(3):235-45

8. Agrawal A, Mahey R, Kachhawa G, Khadgawat $\mathrm{R}$, Vanamail P, Kriplani A. Comparison of metformin plus myoinositol vs metformin alone in PCOS women undergoing ovulation induction cycles: randomized controlled trial. Gynecological Endocrinology. 2019;35(6):511-4

9. Nordio M, Proietti E. The combined therapy with myo-inositol and D-chiro-inositol reduces the risk of metabolic disease in PCOS overweight patients compared to myoinositol supplementation alone. Eur Rev Med Pharmacol Sci. 2007;11(5):347-54

10. Nabi S, Guleria R. Comparison of Myoinositol and Metformin in Women with Polycystic Ovarian Syndrome. Clini Cal Study. 2020;30(11):1045-49

11. Nehra J, Kaushal J, Singhal SR, Ghalaut VS. A comparative study of efficacy and safety of myo-inositol versus metformin in polycystic ovarian syndrome in women. World Journal of Pharmacy and Pharmaceutical Sciences. 2016;5(5):884-96

12. Dunaif A, Xia J, Book CB, Schenker E, 
Tang Z. Excessive insulin receptor serine phosphorylation in cultured fibroblasts and in skeletal muscle. A potential mechanism for insulin resistance in the polycystic ovary syndrome. The Journal of clinical investigation. 1995;96(2):801-10

13. Lord JM, Flight IH, Norman RJ. Metformin in polycystic ovary syndrome: systematic review and meta-analysis. Bmj. 2003 Oct 23;327(7421):951.

14. Nagaria T, Mohapatra A, Jaiswal J. Effect of Myoinositol and Metformin in combination on clinical and hormonal profile in patients of polycystic ovarian syndrome. International Journal of Reproduction, Contraception, Obstetrics and Gynecology. 2019;8(2):703
15. Thakur SS, Anjum S, Siddiqui SS. Randomised controlled trial: comparing effects of metformin versus myoinositol versus metformin and myoinositol on ovarian functions and metabolic factors in polycystic ovarian syndrome. International Journal of Reproduction Contraception, Obstetrics and Gynecology.2020;9(6):2543

16. Chirania K, Misra S, Behera S. A randomised clinical trial comparing myoinositol and metformin in PCOS. Int $\mathrm{J}$ Reprod Contracept Obstet Gynecol. 2017;6(5):1814-20

17. Rani M, Singh M. A Study on the efficacy and safety of Myoinositol and Metformin in the treatment of PCOS. Journal name. 2019;7(5):712-6 